\title{
Polymide Super-fiber from Soluble Polymide
}

\author{
Hiroshi Itatani, Taro Itatani* and Tsutomu Takeichi** \\ Solpit, AIST \\ 2-1-1 Sengen Tsukuba, Ibaraki 300-,Japan \\ *Nano-electronics Research Institute, AIST \\ 1-1-1 Umezono Tsukuba Ibaraki 305-8568, Japan \\ ** Toyohashi University of Technology \\ Tenhakumachi, Toyohasi, Aichi 441-8580 Japan
}

\begin{abstract}
We synthesized solvent-soluble polyimide which was composed from 3,3',4,4'-biphenyl tetracarboxylic acid dianhydride(BPDA), 4,4'-bis(4-amino phenoxy) biphenyl(BAPB) and bis(3-amino-4-hydroxyphenyl) sulfone(DABS). Polyimide fiber was obtained by air gap spinning of the solution. Fibers heat-treated at $200 \sim 300^{\circ} \mathrm{C}$ had excellent heat resistance and circle cross-section.
\end{abstract}

Keywords : polyimide, fiber, soluble、 spinnig

\section{Introduction}

While the fibers are used tires and clothing, the nets and the like, fibers of polyester and nylon are used primarily. Fiber that shows at least twice as strong as that, and the high decomposition temperature and high melting point are referred to high-performance fibers.

DuPont have proposed polyimide fibers consisting of pyromellitic acid dianhydride(PMDA) and 4,4 'diaminodiphenyl ether(DADE) [1]. However, the polyimide is solvent insoluble. In order to make fibers synthesized by the polyamic acid precursor of the first, thereby a polyimide fiber is obtained by spinning and heating process of the solution.

The fibrous polyimide "P-84" has been producted from Inspec Fiber Corporation of Australia. This is synthesized from benzophenone tetracarboxylic dianhydride (BTDA) and aromatic isocyanates [2]. Its composition is different from that of the high-performance conventional fiber. Glass transition temperature $(\mathrm{Tg})$ is $315^{\circ} \mathrm{C}$. It could not say with high heat resistance for that. On the other hand, while polyimide has excellent heat resistance even in the polyimide, it is slightly soluble in a solvent such as NMP.

Fibers and films have a excellent heat resistance in polyimide structure, and prepared directly from the polyimide solution, which makes them difficult until now. Recently in order to improve the properties of the polyimide by two or three step polymerization process of the polyimide polymer, we have succeeded in the production of heat-resistant polyimide that is soluble in a solvent such as NMP easily.[3]. Polyimide soluble in solvents such as N-methyl-2pyrrolidone(NMP) is synthesized in NMP solution in the presence of pyridine valerolactone catalyst by condensation of a diamine and a dicarboxylic acid anhydride.

Polyimide film was created by casting the polyimide solution followed by heating and removing the solvent. In this study, we investigated a method of manufacturing a heat-resistant polyimide fiber from the heat resistance of solvent-soluble polyimide.

\section{Experimental}

2.1. Polymerization of polyimide

BPDA were used as received from Ube Industries, Ltd. PMDA and DADE, were used as received from the Tokyo Kasei Kogyo Co. Ltd. BAPB, DABS and 4,4' -(9- fluorenylidene) dianiline (FDA) were used as received from Wakayamaseikakogyo Co. Ltd. NMP, toluene, pyridine, valerolactone were purchased from Wako Pure Chemical Industries Ltd. The raw material monomer compositions of the polymerization are shown in Table 1. 
Table 1 monomers

\begin{tabular}{|c|c|c|c|}
\hline No & State & Acid & Amine \\
\hline 1 & Polyimide & 3 BPDA & BAPB+DABS +DADE \\
\hline 2 & Polyimide & 3 BPDA & BAPB+DABS+DADE \\
\hline 3 & Polyimide & 3 BPDA & BAPB+DABS+DADE \\
\hline 4 & Polyimide & 3 BPDA & BAPB+2FDA \\
\hline 5 & Polyimide & 2 BPDA & BAPB+HFBAPB \\
\hline 6 & Amick acid & BPDA & PPD \\
\hline 7 & Amick acid & BPDA & DADE \\
\hline 8 & Amick acid & PMA & DADE \\
\hline
\end{tabular}

The raw material monomers were polymerized by using the four-neck separable glass flask of $1 \mathrm{~L}$ attached nitrogen inlet tube, a stirrer and a condenser with a water separator trap. A two polymerization step condition was carried out in the polymerization No.1

In the first step reaction, solvent NMP180g, BPDA $17.72 \mathrm{~g}$ and BAPB7.36g were added to the reaction vessel as a raw material. And then toluene $20 \mathrm{~g}$, pyridine $3.0 \mathrm{~g}$ and valerolactone $2.0 \mathrm{~g}$ were added in addition as a catalyst. The solution was stirred while passing nitrogen gas, and the reaction vessel was heated one hour at silicon oil bath at $180{ }^{\circ} \mathrm{C}$.

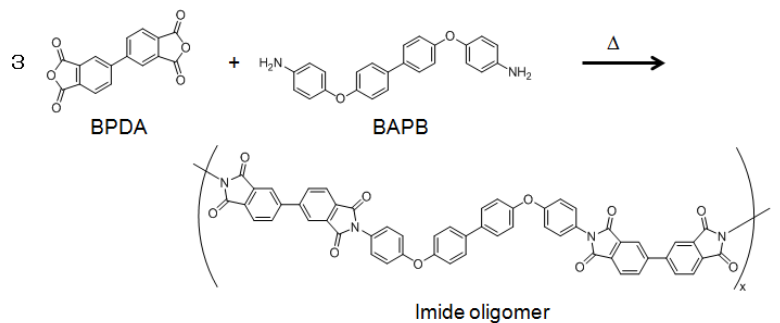

Equation 1.

The reactor was air-cooled, as a raw material, and was added with NMP50g 3,3 '-DABS 5.60g, DADE 4.00g. The second step reaction was continued for 4 hours, then heated and stirred again. To obtain a polyimide solution the reactor was cooled down to room temperature.

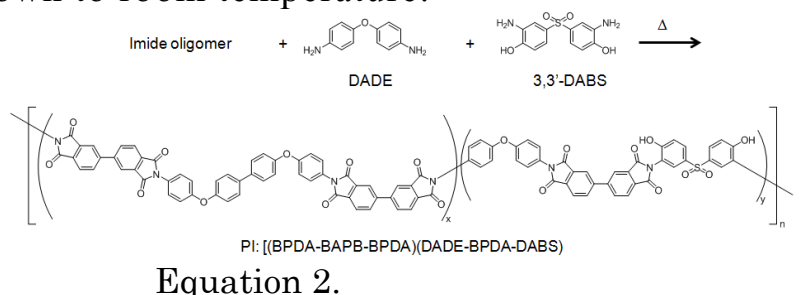

For samples No.6 to No.8, amic acid polymer was synthesized in NMP solvent and was added to the reactor with the raw material acid and amine under heating and stirring at $60^{\circ} \mathrm{C}$ for 4 hours.

\subsection{Film production for evaluation}

Polyimide solution is applied to a thickness of $200 \mu \mathrm{m}$ on a clean glass plate and heated for 60 minutes each at $180^{\circ} \mathrm{C}$ and $250^{\circ} \mathrm{C}$, and then, the sample after removal of the solvent was peeled from the glass plate.

\subsection{Polyimide spinning}

The image of the spinning process by an air gap and the image of the heat treatment process are shown in Figure-1
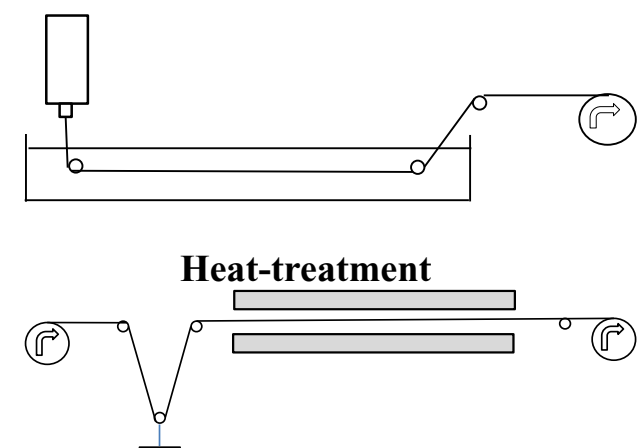

Fig. 1 Image of air-gap spinning.

\section{Results and discussion}

3.1. Properties of the polyimide solution

The resulting polymer solution was clear in all viscous. The molecular weight was measured by GPC (HLC-8320 manufactured by Tosoh Corporation).

Table 2 Molecular weight of polyimide

\begin{tabular}{|l|c|c|}
\hline \multirow{2}{*}{ No. } & \multicolumn{2}{|c|}{ GPC(PS converted molecular weight) } \\
\cline { 2 - 3 } & Mn & Mw \\
\hline 1 & 98,000 & 212,000 \\
\hline 2 & 86,000 & 175,000 \\
\hline 3 & 41,000 & 87,000 \\
\hline 4 & 32,000 & 78,000 \\
\hline 5 & 67,000 & 146,000 \\
\hline 6 & 44,000 & 92,000 \\
\hline 7 & 62,000 & 111,000 \\
\hline 8 & 57,000 & 108,000 \\
\hline
\end{tabular}

The results were shown in Table 2 . The results show all the high molecular weight. Then evaluated uniform film was obtained. The film did not show any change even after 
one month in further properties of the polyimide solution.

\subsection{Thermal properties of the polyimide film}

The thermal properties of the polyimide film were measured by using TGA and DSC. And a high thermal stability was achieved as shown in Table 3.

Table 3 Thermal property of the polyimide film

\begin{tabular}{|c|c|c|c|l|}
\hline \multirow{2}{*}{$\begin{array}{l}\text { No } \\
.\end{array}$} & \multicolumn{3}{|c|}{$\mathrm{Td}\left({ }^{\circ} \mathrm{C}\right)$} & $\mathrm{Tg}\left({ }^{\circ} \mathrm{C}\right)$ \\
\cline { 2 - 5 } & - & $\mathrm{Td}(3 \%)$ & $\mathrm{Td}(5 \%)$ & \\
\hline 1 & 406 & 428 & 453 & $\begin{array}{l}\text { Unfoun } \\
\mathrm{d}\end{array}$ \\
\hline 4 & 554 & 545 & 566 & $\begin{array}{l}\text { Unfoun } \\
\mathrm{d}\end{array}$ \\
\hline 5 & 526 & 526 & 540 & 258 \\
\hline 8 & 558 & 564 & 573 & 268 \\
\hline
\end{tabular}

Note: In DSC measurement, the sample was heated at $250{ }^{\circ} \mathrm{C}$ in a single scan, and then allowed to cool down to room temperature. After that, Tds were measured. In the Table "unfound" means that $\mathrm{Tg}$ is not detected by DSC chart or DTA.

\subsection{Spinning}

Table 4 shows the results of the air gap spinning in various polyimide and amick acid.

Table 4 Yarn of various polymers

\begin{tabular}{|c|c|c|c|c|}
\hline & $\begin{array}{c}\text { Solution } \\
\text { viscosity } \\
\text { (poise) }\end{array}$ & $\begin{array}{c}\text { State of the } \\
\text { Spinning }\end{array}$ & $\begin{array}{c}\text { State of } \\
\text { the Fiber }\end{array}$ & $\begin{array}{c}\text { Strength } \\
\text { of the } \\
\text { fiber }\end{array}$ \\
\hline 1 & 360 & good & good & Strong \\
\hline 2 & 180 & good & good & Strong \\
\hline 3 & 17 & Fall down & & Fragile \\
\hline 4 & 31 & fall down & & Fragile \\
\hline 5 & 102 & good & whitens & Fragile \\
\hline 6 & 520 & good & whitens & Fragile \\
\hline 7 & 300 & good & whitens & Fragile \\
\hline 8 & 200 & whitens & whitens & Fragile \\
\hline
\end{tabular}

The polymer solution having viscosity of less than 100 poise can not spun continuously by poor spinnability. We have found that in order to obtain the continuous fibers the solution viscosity is at least 100 poise.

The amick acid solution was a polyimide precursor of Kapton and Upilex whitened and a polymer was crystallized as soon as it was in the water. The solution was spun continually. However, the fiber was runned out on a bobbin for the dry shrinkage when air was dried at room temperature, because the provided fiber was fragile. Therefore, the heat-treatment of the fiber was not possible. Even soluble polyimide was not over so that fragile fiber was provided from the polymer composition which was whitened with water. As spun fiber was immersed in water more than 30 minutes and the fiber removed NMP was heat-treated at less than $200^{\circ} \mathrm{C}$ (less TG). The spun fiber was impossible for excessive extension and runned out of thread. We have assumed that the NMP remained in the yarn is lowered at the $\mathrm{Tg}$ of the fibers.

Table 5 Relations of dry condition and residual NMP about the yarned fiber

\begin{tabular}{|l|c|c|c|c|c|c|}
\hline Residu & Diame & \multicolumn{5}{|c|}{ Dry temperature $\left({ }^{\circ} \mathrm{C}\right)$} \\
\cline { 3 - 7 } & $\begin{array}{l}\text { ter of } \\
\text { Fiber }\end{array}$ & 25 & 150 & 200 & 250 & 300 \\
\hline \multirow{2}{*}{$\begin{array}{l}\text { NMP }( \\
\text { wt\% }\end{array}$} & $60 \mu \mathrm{m}$ & 14.8 & 11.1 & 3.7 & 3.7 & 0 \\
\cline { 2 - 7 } & $30 \mu \mathrm{m}$ & 8.6 & 7.4 & 6.7 & 4.7 & 0 \\
\hline
\end{tabular}

Residual NMP is assumed zero in the fiber for 30 minutes (Note) at $300{ }^{\circ} \mathrm{C}$.

Removal of NMP from the fiber was very difficult. It was considered that the coagulation bath and heat treatment process was essential.

Table 6 shows the relationship between the heat treatment conditions and tensile properties of fiber, where (3BPDA)(BAPS+ DABS+DADE)composition is spinnable and heat treated. The elongation of the heat treated fiber was decreased and improved by heat treatment. Fiber tensile strength and modulus was improved by heat treatment.

Fig. 4 and 5 show fiber ross-sectional shape obtained by dry spinning to remove the solvent at high temperature and air gap spinning.

Cross-sectional shape of the fibers obtained in dry spinning polymer solution was cocoon type but cross-sectional shape of the fibers obtained in air gap spinning was circular.

There was a problem that the fiber cross-section shape of cocoon type showed poor transport to the processing time for such a woven fabric. The machine operating efficiency was lowered. Fibers were appeared and the problem was solved in circular cross-section.

Conventional polyimide fibers were made, because it was necessary to produce a polyamide fiber at a time from the 
Table 6 heat-treatment temperature and fiber properties

\begin{tabular}{|c|c|c|c|c|c|c|c|}
\hline & \multirow{2}{*}{\multicolumn{3}{|c|}{ heat-treatment }} & Finnnes & Elongation & Modurus & Strength \\
\hline & & & & dtex & $\%$ & $\mathrm{cN} / \mathrm{dtex}$ & $\mathrm{cN} / \mathrm{dtex}$ \\
\hline as-spun & \multicolumn{3}{|c|}{$\begin{array}{l}\text { Fiber dry at room } \\
\text { temperature }\end{array}$} & 15.1 & 116 & 21 & 0.9 \\
\hline \multirow{3}{*}{ Hea-set } & 250 & 250 & 250 & 15.1 & 13 & 25 & 1.0 \\
\hline & 200 & 300 & 300 & 4.3 & 21 & 59 & 4.4 \\
\hline & 200 & 300 & 350 & 4.3 & 21 & 59 & 4.2 \\
\hline
\end{tabular}

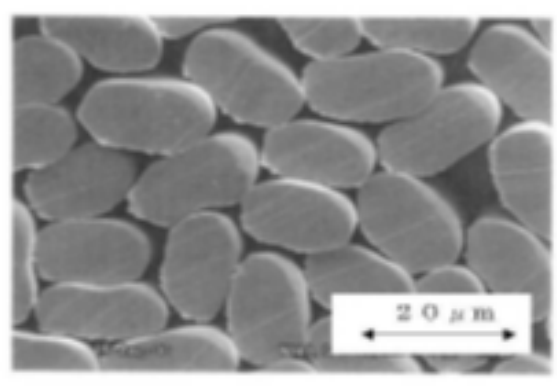

Fig. 5 Dry spinning fiber [4].
Fig.2 Effect of heat treatment on modurus

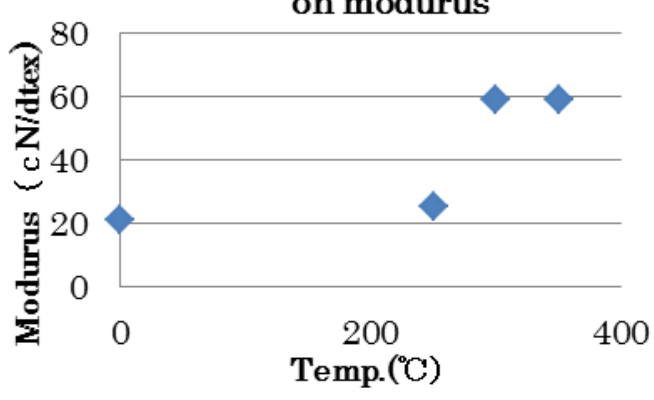

Fig. 3 Effect of heat tratment on tensile strength
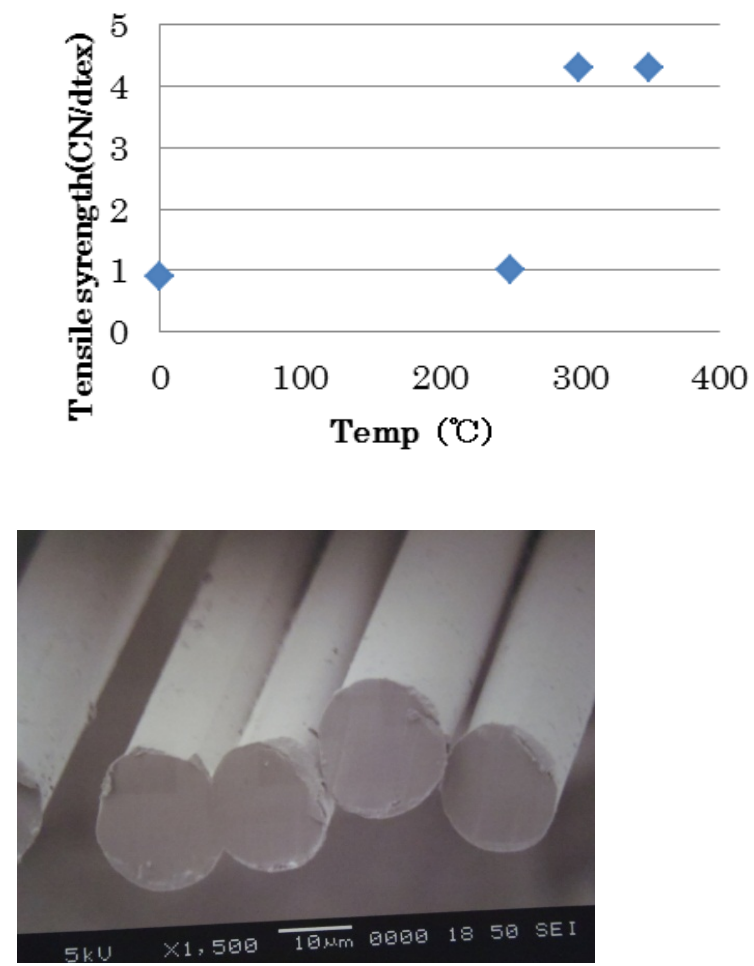

Fig.4 Air-Gap spinning fiber.

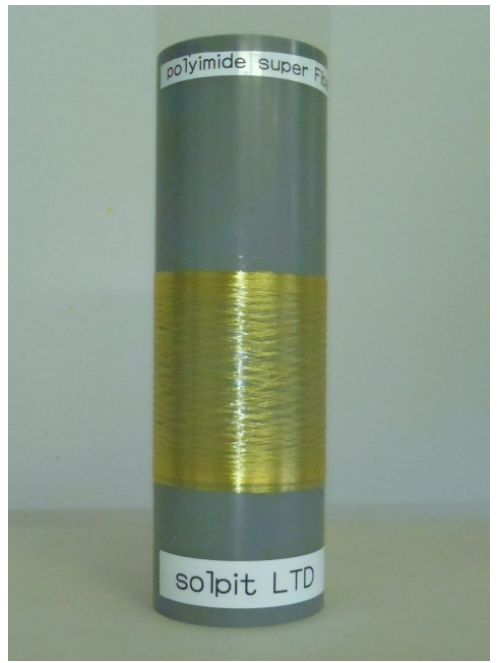

Fig. 6 Polyimide super fiber.

polyamickacid solution, such as by heating the imidization. Polyamide fibers were used for precursor of polyamick acid.

Polyamide fibers were directly ejected into the water under the atmosphere. Soluble polyimide solvent was not whitened in water filed, because it was necessary to produce a fiber node. The fiber was imidized such as by heating the polyamide fiber. It was stretched in a solution of the polyimide. After obtaining the spun fibers coagulated, a polyimide fiber having excellent heat resistance was fabricated. The residual solvent was removed by evaporation and heating with successively at $100{ }^{\circ} \mathrm{C}, 200{ }^{\circ} \mathrm{C}$ and $300{ }^{\circ} \mathrm{C}$. It was soluble and have excellent tensile strength.

The Polyimide structure used here was the solvent-soluble polyimide, A structural units BPDA was designed and added to the amino groups at both ends of BAPB. This solvent-soluble polyimide had a linear structure suitable for manufacturing polyimide fiber. Also, the 3,3 '-DABS was a 
diamine component, and contributed for prohibiting the whitening caused by solidification in water. This is the reason why this polyimide is suitable for spinning in this method.

\section{Summary}

Since the conventional heat-resistant polyimide is not dissolved in the solvent, there is a disadvantage in polyimide film and polyimide fiber manufacturing process is complicated. We have obtained polyimide fibers having excellent heat resistance and tensile strength of the circular cross-sectional shape from soluble polyimide.

\section{Acknowledgment}

We will continue the study with Mr. Seiji Ishikawa Soipit Industry which have carried out the design and guidance of the spinning apparatus. We are extremely grateful to $\mathrm{Mr}$. Kenji Kanayama and Mikawa Textile Technology Center

\section{References}

1. Japanese Patent, 42-2936 (1967).

2. Japanese Patent, 63-2744 (1988).

3. Journal of the Electronics Industry, Dempa Publication, Decmber Issue (2010).

4. Japanese Patent, 2010-77565 (2010). 